\title{
DEVELOPING KNOWLEDGE BASED DECISION SUPPORT TOOL FOR ENTERPRISE RESOURCES PLANNING (ERP) SOFTWARE SELECTION
}

\author{
Yrd. Doç. Dr. İsmail Erol \\ Abant lzzet Baysal Üniversitesi \\ Iktisadi ve Idari Bilimler Fakültesi
}

\author{
Dr. Mehmet Barut \\ Wichita State University \\ Barton School of Business
}

\section{Kamusal Kaynak Planlamast Yazlımı Seçiminde Bilgiye Dayah Karar Destek Aracı Geliştirilmesi \\ Özet}

Kurumsal kaynak planlaması (ERP) gibi kapsamlı bir yazılım sistemini satın almak, yoğun bir finansal etkiye sahip olan ve buna ek olarak sayısal ve sayısal olmayan bilgiye dayalı bir projedir. Bu tip durumlarda, analitik araçları kullanmak büyük bir yarar sağlar. Bununla birlikte, temel olarak farklı olan bilgileri bir modelde bir araya getirmek büyük bir zorluk meydana getirir. Bu makale, sayısal ve sayısal olmayan faktörler ve birden fazla amac göz önüne almak arzu edilen bir durum olduğunda en iyi ERP paketini seçebilecek bir metod öneriyor. Bu metod, üç bölümden olumaktadır: (1) Bilgi toplanması ve ölçümlemesi, (2) toplam kullanucı tercihlerinin hesaplanması, ve (3) birden fazla amaçh optimizasyon. llk iki bölüm, sonradan birden fazla amaçlı optumizasyon modeline girdi olacak sayısal olmayan bilgileri sayısal parametrelere dönü̊türüyor. Metod, A.B.Dödeki bir elektronik parça üreticisinin ERP seçim sürecine uygulanuyor ve sonuçlar sunuluyor.

Anahtar Sözcükler: Kurumsal kaynak planlaması, bilgiye dayalı karar sistemleri, karışı tamsayilı amaç programlaması, müşteri memnuniyeti, bulanık mantık.

\section{Abstract}

Purchasing a large software system like Enterprise Resources Planning (ERP) is a project with significant financial impact and involves making a decision based on both qualitative and quantitative information. In these types of situations, analytical tools are invaluable; however, combining fundamentally different data into a single model is quite a challenge. This paper proposes a methodology to select the best ERP product when it is desirable to consider multiple objectives with both qualitative and quantitative factors. The methodology involves three elements: (1) data acquisition and assessment, (2) calculation of total user preferences, and (2) multiobjective optimization. The first two elements translate qualitative information into quantitative parameters that are then input to the final element, multiobjective optimization. The methodology is applied to an electronic component manufacturer's ERP selection process and the results are presented.

Key Words: ERP, knowledge based decision support systems, mixed integer goal programming, customer satisfaction, fuzzy logic. 


\section{Developing Knowledge Based Decision Support Tool for Enterprise Resources Planning (ERP) Software Selection}

\section{Introduction}

Today's companies are striving to make their operations leaner and agile whose obvious implications are speed and flexibility. To ensure that, companies must invest in certain structural prerequisites such as continuous improvement, $R \& D$, advanced technologies, and integration of people and systems. Among these, the latter is the most challenging prerequisite and requires an enterprise wide integration in order to generate and communicate information more rapidly and accurately. This endeavor usually entails making the right decision among a limited number of alternatives. A purchasing decision of an enterprise-wide information system such as Enterprise Resources Planning (ERP) is a quite complicated decision since both qualitative and quantitative issues need to be considered. Due to large investment of time and money involved, the selection process of ERP systems has become a big business for consulting firms as well as for the software vendors themselves. Selecting the right software for the operation can be an extremely difficult undertaking, even with outside assistance. While quantitative tools are extremely valuable in alleviating this process, effectively combining fundamentally different data into a single model such that the relative importance accurately reflects the reality is quite a challenge. This paper presents a methodology for making such a selection when both qualitative and quantitative data must be considered. In addition, our experience suggests that not only do selection problems contain both qualitative and quantitative data, but also most are actually multi-objective, which reflects the compromise between user satisfaction and total cost.

The purpose of this research, therefore, is to build a knowledge-based decision support (KBDS) tool that integrates fuzzy quality function deployment (QFD) and the method of total preferences with multi-objective optimization to address the selection problem described. 
The paper is organized as follows: we first present a review of the existing literature on the techniques used. This is followed by a brief discussion concerning ERP selection and the necessity of a knowledge based tool. After describing the proposed methodology in detail, we report the results of a real case study that illustrates an electronic component manufacturer's ERP software selection process employing the proposed KBDS tool. Finally, we discuss the implications of using this tool.

\section{Literature review}

There is an abundance of excellent research concerning the problem of selecting from among a fixed number of alternatives, most of which directed towards specific applications. Bernroider and Korch (2001) detailed the results from an empirical study concerning differences in characteristics of the enterprise resource planning (ERP) system selection process between small or medium and large sized organizations. In particular, they addressed the fields of software packages considered and chosen, the weights assigned to different selection criteria, the size and structure of the team responsible for the decision, the methods employed and the effort expended. Lai, Wong and Cheung (2002) displayed a case study where the analytic hierarchy process (AHP) was used to support the selection of a multi-media authorizing system in a group decision environment. Min (1992) used AHP to select the proper logistics software. In addition, many researchers have addressed the problem of selecting suppliers or vendors, which are nothing but selecting from limited alternatives. In his meta-analysis, Weber (1991) reviewed 74 papers that represented the supplier selection literature between 1966 and 1991. Moore and Fearon (1973) were the first to discuss the possible use of Linear Programming (LP) model for vendor selection. Anthony and Buffa (1977) used a LP model to minimize total purchasing and storage costs in scheduling vendor deliveries. Pan (1989) developed an LP model to minimize total purchase price. Handfield, Walton, Sroufe and Melnyk (2002) used AHP to evaluate supplier performances in terms of environmental dimensions. Ghodsypour and O'Brian (1998) proposed a model that integrated AHP and LP to consider both tangible and intangible factors in choosing the best suppliers and placing the optimum order quantities among them such that the total value of purchasing is maximized. Kasilingam and Lee (1996) proposed a Mixed Integer Linear Programming (MILP) model for selecting vendors and determining order quantities. Some authors addressing multiple objectives includes Buffa and Jackson (1983) employing goal programming to consider quality, price and delivery criteria and Weber (1993) developing an approach to minimize the total cost, the total number of late deliveries, and the total number of rejected units. Other research has broached the issue of uncertainty a decision-maker may experience in assigning scores to 
criteria. For example, Thompson (1990) proposed a point rating approach for vendor selection that utilizes Monte Carlo simulation to produce an overall ranking.

Other types of problems that typify selection from limited alternatives have served as the source of solid research as well. Korpela and Lehmusvaara (1999) used the AHP to provide input to a MILP to address the warehouse assignment problem. Min and Schilling (1990) reviewed 45 articles using multiobjective models to resolve the facility location problem.

In summary, the research in the general area of selecting from among a limited number of alternatives is excellent and covers a number of important issues related to the topic. Our work is focused on a niche that we believe is quite important in practice, namely, multiobjective decision making from among a limited number of alternatives when the decision maker must consider both quantitative and qualitative factors simultaneously. The methodology outlined in this paper seeks to address the fundamental ERP software selection problem in a comprehensive and integrated yet practical fashion.

\section{ERP selection and necessity of a knowledge based tool}

Most enterprises can expect to change their ERP information system either to a new system or a major upgrade, at least 5 to 7 years (PTAK / SCHRAGENHEIM, 2000). With rapidly developing technology and the emerging needs of customers, it is crucial that the company make the best choice possible in a new system. This involves the hardware platform, database tool and the overall philosophy of the ERP system. Some ERP systems are well designed for decentralized controls while others offer an excellent fit for corporate standardized business processes. Given that there are hundreds of ERP systems available globally,.how can a company be sure that they got the one that is the best fit?

In a nutshell, the issues prospective teams deal with are as follows: (1) ERP products are all different but each package has different strengths and different weaknesses and they emphasize different parts of the process enablement, (2) the broad functionality of ERP systems makes the selection process just that much more difficult, (3) their selection project teams have no effective way to define their business requirements and thereby identify critical vendor and product criteria necessary to successfully initiate the evaluation process, (4) when these criteria have eventually been pinpointed and submitted to the most appropriate vendors, project teams often lack the ability to effectively prioritize the different criteria relative to their importance to supporting the requirements. Therefore, priorities are derived from internal 
political agendas rather than the true needs and requirements, and (5) they lack an analytical tool to find the best product considering conflicting objectives.

As a result, choosing the right package is not easy (or at least not simple), and choosing the wrong one can be a costly disaster since the implementation of an ERP system requires a large investment of time and money. To facilitate the process, this paper proposes a KBDS tool that consists of ways to rationally input information and then to evaluate the information according to the value requirements of the stakeholders.

\section{The proposed methodology}

Although the problem has thus far been described in terms of decision making and selection, it can also be viewed as an engineering design problem and this observation provides insight into developing a viable strategy for resolution. In particular, a design effort begins by identifying the expectations of a user for a potential product. Expectations, so called "customer requirements", collected as the voice of the user, are subsequently translated into technical specifications on the product so that the designer can manipulate the design features to meet the specifications. ERP software selection problem to meet enterprise-wide expectations has many of the same features. The decision maker is confronted with selecting from among a set of alternatives that meet user expectations to the greatest extent possible. These enterprise-wide expectations are satisfied, to some degree, by attributes possessed by the features of the software. It should be noted that the attributes associated with ERP software or its vendor might be quantitative in nature like the cost or qualitative such as perceived reliability and service support. To accommodate the selection framework, we define 'performance aspects' as the features that the decision maker wishes to consider in the selection process and 'enablers' as the characteristics of each alternative that have the potential to satisfy these performance aspects. For example, an enabler for ERP software or its vendor might be the infrastructure used or the length of the time required for the implementation. The overall selection problem, as a result, is to simultaneously consider the various enablers associated with each alternative relative to their potential impact on the performance aspects. Based on this analysis, the best compromise alternative is chosen.

The proposed methodology is a result of adapting engineering design strategy to the ERP selection problem. The three main elements of the methodology are: 1) data acquisition and assessment, 2) calculation of total user preferences, and 3) multi-objective optimization. Although the first element, data acquisition and assessment, is not the focus of this research, it is incredibly important to any implementation that a practitioner might contemplate; hence, 
we provide a brief discussion of data collection, organizing the data in a central repository, and making preliminary assessments. In the second element, the qualitative data is converted into a quantitative format using the method of total preferences with fuzzy QFD. And, the final phase is to use parameters obtained from the previous phase in a multi-objective optimization model. This model is the appropriate technical tool for the selection problem that is used by decision-makers to finalize a selection by considering resource constraints.

\subsection{Data acquisition and assessment}

For a given situation, data regarding alternative ERP vendors must be collected from a wide variety of diverse places. Approximately 40 or 50 vendors may be included in the analysis. It is imperative that performance aspects and enablers used in the third element, the total calculation of total user preferences, be determined in the beginning of data acquisition to ensure that the required data are gathered. At this point, Group Support Systems (GSS) can be a useful tool to support team interaction and more effectively focus on identifying performance aspects and enablers. They come in a variety of forms, ranging from use of e-mail to software to support meeting rooms, as well as Extranet to expedite communication with vendors and Intranet to facilitate communication within an organization. These systems have been given credit for saving tremendous amounts of organizational time. Olson (2001) states that GSSs can aid group decision process a number of ways: (1) GSS anonymity can reduce individual inhibition and focus attention on ideas in the problem recognition phase of decision making, and (2) Simultaneous input provides more efficient means to generate information and avoid domination by influential group members.

GSSs are especially good at supporting the brainstorming process that involves generating ideas. An additional feature of most GSSs is the ability for all participants to evaluate the comments and ideas that have been generated by the brainstorming process. There is, however, one drawback of brainstorming which is the fact that individuals with dominating personalities can take over brainstorming sessions

Another method that is supported by GSSs is the Delphi Method. The first phase of the Delphi method is anonymous generation of opinions and ideas related to the issue at hand by participants. These anonymous papers are then circulated to all participants who revise their thoughts in light of these other ideas. Anonymous ideas are exchanged for either given number of rounds or until convergence of ideas. The disadvantage is that the Delphi Method is much more time consuming than brainstorming (OLSON, 2001). 
Once performance aspects and enablers have been determined using either brainstorming or the Delphi Method, the next step is to summarize them for potential vendors. A project team generally uses three basic types of documents to achieve this step: a request for quotation (RFQ), a request for proposal (RFP) and a request for information (RFI). With a $R F Q$, a vendor quotes a price for the listed product(s) that meet(s) an organization's requirements and then quotes the price(s). With a RFP, the vendor selects the product(s) that meets. Several software packages exist that assist organizations in creating a professional RFP. Just as the depth of an information system varies so does the length of an RFQ or RFP. Some can be as short as a couple of pages while others consist of more than one hundred pages. Instead of an RFQ or RFP, some companies prefer to use RFI that uses a standard form to request information about a product or service (Shelly, Cashman and Vermaat, 2002). Once vendors have received these documents, they send them back to the customer with completed quotations and proposals, which will be employed in the second and third element of the proposed methodology.

Another source for data gathering is ERP software. scorecard from APICS's Performance Advantage. It is an analysis of the ERP systems currently available and supported in the North American market to determine whether a system can be a good fit for a company of a specific size, doing business in a specific industry, and operating in a specific manufacturing environment.

Clearly, quality and integrity problems are the paramount concerns because populating even the best models with poor data will generate poor results. It is important to carefully scrutinize the data using manual and/or electronic means. Inconsistent data must either be evaluated to determine if it is real or if it is spurious. This raw data must then be stored and catalogued, preferably in a data warehouse. A data warehouse is a specialized database that provides integrated, relevant and consistent information (FIORE, 1999). It holds a wide variety of information that might include vendors, characteristics of their products and their performance evaluations. As mentioned before, this step is critical in applying this methodology and will probably be the most time-consuming.

In this element, screening is also very desirable because it reduces the dimension of the decision problem by eliminating alternatives that cannot meet one or more of the requirements.

\subsection{Calculation of Total User Preferences}

This element of the methodology determines team member's preferences for alternative ERP products by using fuzzy QFD and the method of total preferences. 


\subsubsection{Fuzzy QFD}

QFD, originated in Japan in the late 1960 s, is a concept and mechanism for translating the voice of the customer into product features through various stages of product planning, engineering and manufacturing (AKAO, 1990). This translation process begins with determining the underlying constituents of QFD, which are performance aspects and enablers. Then, the importance of performance aspects and the relationships between performance aspects and enablers are computed. The final process is to obtain the degree to which each enabler affects performance aspects. Until the early 1990s, researchers used traditional approaches to calculating the importance of performance aspects and the relationship scores. For example, whereas some numerical scales, such as $1-3-5,1-3-9$ or 1-5-9, were the basis of the relationships between performance aspects and enablers, percentage values between 0 and 1 were assigned to quantify the importance of performance aspect.

There are two problems associated with this approach: (1) even though each individual may have varying perceptions of a particular linguistic variable, numerical scales assign the same value to it, and (2) the choice of scales can influence the outcome dramatically.

To overcome the subjectiveness factor that may degrade the value of QFD as a design methodology, Masud and Dean (1993) treated the weights of customer requirements and the relationships between customer and technical requirements as triangular fuzzy numbers. Lu (1994) became the first to apply the AHP to determine the importance of performance aspects. Kho and Ho (1996) used fuzzy numbers in order to represent the uncertainty of judgments in the assignment of relationship strength. Temponi, Yen and Tiao (1999) stated that using fuzzy logic to capture the meaning of the linguistic terms not only allow different parties to communicate in natural language but also facilitate expression of customer's needs and expert's knowledge. They considered different impacts of satisfying a requirement on the satisfaction degree of another requirement and identified four types of significant relationships between requirements: mutually exclusive, irrelevant, conflicting and cooperative. Then, they developed fuzzy if-then heuristic rules to reason about partially conflicting or partially cooperative relationships. Vanegas and Labib (2001) used fuzzy numbers to represent the imprecise nature of the judgments and to define more appropriately the relationships between customer requirements and technical requirements. They also employed fuzzy QFD to determine the importance of customer requirements and proposed the new fuzzy weighted average to determine the effect of engineering characteristics on customer satisfaction. Kim, Moskowitz, Dhingra and Evans (2000) developed fuzzy regression model to calculate the parameters of QFD. Sohn and Choi 
(2001) established a fuzzy QFD approach in order to find the optimal levels of design variables.

Fuzzy QFD approach in this research employs fuzzy arithmetic to establish a structured methodology that converts qualitative data into numerical values. However, it also uses fuzzy information processing based on the methodology developed by Juang, Huang and Elton (1991) who presented a new method utilizing Monte Carlo simulation. It is imperative at this point to emphasize that since fuzzy QFD approach proposed in this paper does not require determining the optimal levels of enablers but simply the significance of them in terms of performance aspects, we basically apply fuzzy arithmetic to the linguistic expressions on the relationships and the importance of performance aspects.

Consistent with conventional QFD, the proposed fuzzy QFD uses a process with several distinct steps to link performance aspects and enablers. The first step involves ranking each performance aspect relative to the other performance aspects and providing a measure of the strength of interaction between each performance aspect and enabler. Let the ranking of the performance aspect $i$ relative to all other performance aspects and the strength of the relationship between performance aspect $i$ and enabler $j$ be di and Rij, respectively. The absolute technical importance ratings (ATIRs) are computed by:

$$
\operatorname{ATIR}_{j}=\sum_{i=1}^{l} d_{i} * R_{i j} \vee \mathrm{j}=1 \ldots \mathrm{J}
$$

and represent the degree to which each enabler can satisfy the set of performance aspects. In order to easily compare the effectiveness of the ATIRs, they are frequently normalized to form the relative technical importance ratings (RTIRs) using the uquations

$$
R T I R_{j}=\frac{A T I R_{j}}{\sum_{j=1}^{J} A T I R_{j}} V \mathrm{j}=1=\ldots \mathrm{J}
$$

The difference between traditional QFD and our proposed fuzzy QFD is the methodology used to determine the $d_{i} S$ and $R_{i j}$. The goal is to more accurately quantify the human input and provide consistency in computations so that the concerns listed earlier are addressed knowing the fact that there is no generally accepted method to determine these parameters. Our version of fuzzy QFD simultaneously employs fuzzy sets and Monte Carlo simulation to calculate these parameters. 
The approach begins with human input from a number of team members using one of a finite number of linguistic variables, $L V_{k}, k=1,2, \ldots, K$. For example, suppose the team members are asked to characterize the relationship between a particular performance aspect and enabler as 5-point-interval scale: very strong, strong, medium, weak, or none. These are assigned the notation $L V_{1}=$ very strong, $\mathrm{LV}_{2}=$ strong, $\mathrm{LV}_{3}=$ medium, $\mathrm{LV}_{4}=$ =weak, and $L V_{5}=$ none. Each of these descriptors is then treated as a fuzzy set, bounded to a predetermined interval, and characterized by a single probability distribution. If the range for this example is the interval 0,10 , one set of assignments for each linguistic variable can be illustrated as in Figure 1.

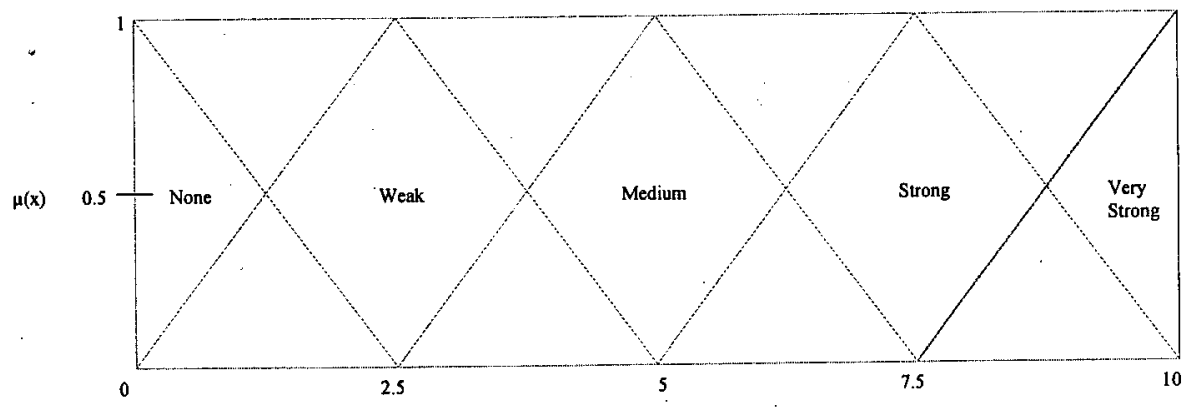

Figure 1: Fuzzy conversion score

Notice that intervals associated with different linguistic variables may overlap to reflect the existence of inherent fuzziness of adjacent words, such as strong and very strong.

This appears reasonable because natural language terms are inherently vague and the boundary of a term should be a region where the term gradually moves from being applicable to non-applicable (CHEN, 1992). The triangle distribution used to model the membership function is chosen because it is frequently used to translate linguistic terms to fuzzy numbers when the exact form of the distribution is not known (PEGDEN, 1995). Values in these intervals are then used as inputs to a Monte Carlo simulation whose output is then used for further computations.

Before describing how linguistic responses are quantified, we emphasize one of the key concepts from fuzzy set theory used in this research, which is called a membership function. A membership function of a fuzzy set $\AA$ relates the possible quantitative values the linguistic response may take and probability values that will be selected. For example, Figure 2 illustrates a triangle membership function that describes a single linguistic response. 
If $x, a, b, c \in R, a<b<c$, and $R=(-\infty, \infty)$, the membership function, $\mu_{\AA}(x)$, is defined as:

$$
\mu_{A}(X)= \begin{cases}(x-a) /(b-a), & a \leq x \leq b \\ (c-x) /(c-b), & b \leq x \leq c \\ 0, & \text { otherwise }\end{cases}
$$

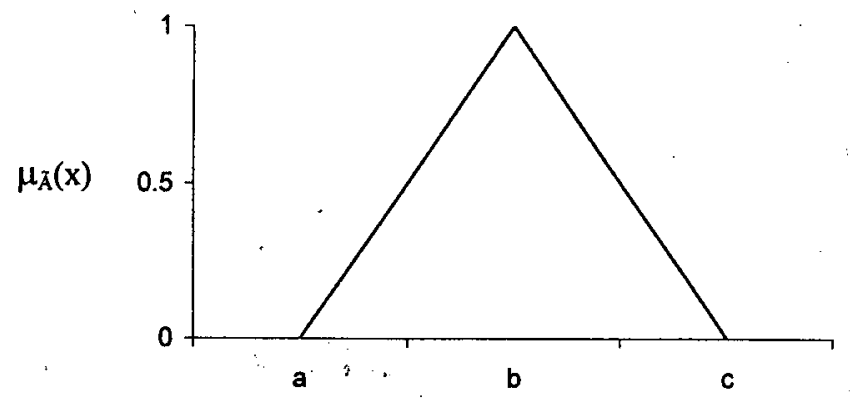

Figure 2: Triangular membership function

To quantify a human response, Monte Carlo simulation is used to generate a value of the membership function corresponding to associated linguistic variable. If desired, several replications can be used and averaged; however, since we are using a well-defined triangle distribution to offset lack of better information, a single replication is called to be sufficient.

Relative to this research, the methodology assumes that several experts are available to express their rankings of the performance aspects and the relationships between performance aspects and enabler pairs. The proposed fuzzy QFD uses Monte Carlo simulation to quantify each response from the membership function and then averages the responses to achieve the final result. Table 1 provides a mathematical illustration of the membership functions displayed in Figure 1.

\begin{tabular}{|l|l|l|l|}
\hline Fuzzy set & Membership function & Domain & Triangular (min, mod, max) \\
\hline Very strong & $\mu(\mathrm{x})=(\mathrm{x}-7.5) /(10.0-7.5)$ & $7.5 \leq \mathrm{x} \leq 10.0$ & $7.5,10.0,10.0$ \\
Strong & $\mu(\mathrm{x})=(10.0-\mathrm{x}) /(10.0-7.5)$ & $7.5 \leq \mathrm{x} \leq 10.0$ & $5.0,7.5,10.0$ \\
& & $5.0 \leq \mathrm{x} \leq 7.5$ & \\
Medium & $\mu(\mathrm{x})=(7.5-\mathrm{x}) /(7.5-5.0)$ & $5.0 \leq \mathrm{x} \leq 7.5$ & $2.5,5.0,7.5$ \\
& & $2.5 \leq \mathrm{x} \leq 5.0$ & \\
Weak & $\mu(\mathrm{x})=(5.0-\mathrm{x}) /(5.0-2.5)$ & $2.5 \leq \mathrm{x} \leq 5.0$ & $0.0,2.5,5.0$ \\
& & $0 \leq \mathrm{x} \leq 2.5$ & \\
None & $\mu(\mathrm{x})=(2.5-\mathrm{x}) /(2.5-0)$ & $0.0,0.0,2.5$ \\
& & & \\
\hline
\end{tabular}

Table 1: Fuzzy Set and membership functions 
Now suppose $M$ experts provide their opinion on the relationship between performance aspect $i$ and enabler $j$ using these linguistic variables given. The relationship score is calculated by:

$\mathbf{R}_{\mathrm{ij}}=\frac{\sum_{\mathrm{m}=1}^{\mathrm{M}}\left[\operatorname{triang}\left(L V_{k}^{m}\right)\right]}{M} \mathrm{~V}_{\mathrm{i} \text { and } \mathrm{j}}$

where

MSC [triang $\left(\mathrm{LV}_{\mathrm{k}}^{\mathrm{m}}\right)$ ] = Monte Carlo simulation value for linguistic variable that was chosen by the expert $m$

The same process is repeated for each performance aspect - enabler pair to generate the entire set of relationship scores.

The relative importance of the performance aspect is similarly computed. The opinion of human experts concerning the ranking of each performance aspect is obtained. Although the terms used for the descriptions are likely different from those used to describe the relationship, we again denote the possible expressions LVk and define:

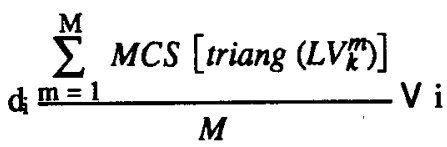

Once $d_{i} s$ and $R_{i j} s$ have been calculated, $R T I R_{j} s$ are determined using equations (1) and (2). Hence, the degree to which each enabler satisfies performance aspects are computed.

\subsubsection{The Method of Total Preferences}

At this point, the linguistic input from cross functional team members has been quantified and an overall measure of how effectively each enabler satisfies the set of performance aspect has been computed via the ATIRs and RTIRs. Recall that the class of problems addressed by this methodology is restricted to decisions that require selecting from a finite set of alternative ERP products when there are multiple, conflicting objectives and the third functional element in the methodology is a multiobjective optimization model. The next step is to convert the information thus far developed into a format suitable to a mathematical programming model. The method of total preferences performs this function by using the RTIRs with additional member opinion to develop a single measure that reflects the total user preference for an alternative $n$, denoted by TUP ${ }_{n}$, which is computed as 
$T U P_{n}=\sum_{j=1}^{J} R T I R_{j} * W A_{n j}$ for every alternative $\mathrm{n}$

where

$W A_{n j}=$ the degree to which alternative $n$ can deliver enabler $j$

$\operatorname{TUP}_{\mathrm{n}}=$ the total user preference for alternative $n$.

Finally, the normalized total user preference for alternative $n, \operatorname{NTUP}_{n}$ is calculated by:

$N T U P_{n}=\frac{T U P_{n}}{\sum_{n=1}^{N} T U P_{n}}$ for every alternative $\mathrm{n}$

A summary of formulations for a prototype problem is illustrated in Table 2.

\begin{tabular}{|c|c|c|c|c|c|}
\hline & Alternative 1 & Alternative 2 & Alternative 3 & $\ldots$ & Alternative $\mathbf{N}$ \\
\hline Enabler 1 & $\mathrm{RTIR}_{1} * \mathrm{WA}_{11}$ & $\mathrm{RTIR}_{1} * \mathrm{WA}_{21}$ & $\mathrm{RTIR}_{1} * \mathrm{WA}_{31}$ & $\ldots$ & $\mathrm{RTIR}_{1} * \mathrm{WA}_{\mathrm{N} 1}$ \\
\hline Enabler 2 & $\mathrm{RTIR}_{2} * \mathrm{WA}_{12}$ & $\mathrm{RTIR}_{2}{ }^{*} \mathrm{WA}_{22}$ & $\mathrm{RTIR}_{2} * \overline{\mathrm{WA}}_{33}$ & $\ldots$ & $\mathrm{RTIR}_{2} * \mathrm{WA}_{\mathrm{N2}}$ \\
\hline : & - & & • & . & \\
\hline Enabler $\mathbf{j}$ & $\mathrm{RTIR}_{\mathrm{j}}{ }^{*} \mathrm{WA}_{1 \mathrm{j}}$ & $\mathrm{RTIR}_{\mathrm{j}}{ }^{*} \mathrm{WA}_{2 \mathrm{j}}$ & $\mathrm{RTIR}_{\mathrm{j}} * \mathrm{WA}_{3 \mathrm{j}}$ & $\cdots$ & $\operatorname{RTIR}_{\mathrm{j}}{ }^{*} \mathrm{WA}_{\mathrm{Nj}}$ \\
\hline $\mathrm{TUP}_{\mathrm{n}}$ & $\sum_{j=1}^{J} R T I R_{j} * W A_{1 j}$ & $\sum_{j=1}^{J} R T I R_{j} * W A_{2 j}$ & $\sum_{j=1}^{J} R T I R_{j} * W A_{3 j}$ & $\ldots$ & $\sum_{j=1}^{J} R T I R_{j} * W A_{N j}$ \\
\hline NTUP $_{n}$ & $\frac{T U P_{1}}{\sum_{n=1}^{N} T U P_{n}}$ & $\frac{T U P_{2}}{\sum_{n=1}^{N} T U P_{n}}$ & $\frac{T U P_{3}}{\sum_{n=1}^{N} T U P_{n}}$ & $\cdots$ & $\frac{T U P_{N}}{\sum_{n=1}^{N} T U P_{n}}$ \\
\hline
\end{tabular}

Table 2: Total User Preferences

Clearly, there is a missing piece in the above calculations, namely, how to determine the degree to which each enabler $n$ can deliver enabler $j, W A_{n j}$. These variables must be computed from input provided by the decision maker in his or her language. Note that the data gathered in data acquisition and assessment element is employed here in order for decision makers to generate their linguistic responses regarding alternatives in terms of each enabler. We propose that the same strategy used to compute the $d_{i} s$ be used to compute the $W A_{n j} s$. As before, let $L V_{k}$ denote a linguistic response describing the degree to which the decision maker believes a particular enabler can be delivered by a specified alternative. The linguistic variables are then translated into fuzzy sets and the fuzzy sets are converted into numbers using Monte Carlo simulation. Hence, 
$W A_{n j} \frac{\sum_{m=1}^{M} M S C\left(L V_{k}^{m}\right)}{M} \mathrm{n}=1, \ldots, \mathrm{N}$ and $\mathrm{j}=1, \ldots, \mathrm{J}$

where

MCS [triang $\left(L V_{k}^{m}\right)$ ] Monte Carlo simulation value for linguistic variable $L V_{k}$ that was chosen by expert $m$

At this point, the data from the first functional element is in an appropriate format for the multiobjective model that will assist the human decision maker. The quantitative data was not altered; however, the qualitative data has been quantified in the form of the NTUPs.

\subsection{Multi-Objective Model}

The last element of the KBDS tool in an ERP selection problem is the multiobjective model. Obviously, no single model is capable of being applicable to all selection problems; rather, at this point in the methodology a model must be built that represents the situation at hand. Here, we consider the classic conflict that frequently exists between maximizing user satisfaction and minimizing cost. Using the $N T U P_{n}$ developed above and letting $T C_{n}$ represent the total cost of alternative $n$, these objective functions of this general class of problems can be represented as:

Maximize TUS $=\sum_{n=1}^{\mathrm{N}} \mathrm{NTUP}_{\mathrm{n}} * X_{n}$ and Minimize $\mathrm{TC}=\sum_{\mathrm{n}=1}^{\mathrm{N}} \mathrm{TC}_{\mathrm{n}} * X_{n}$

st

$\vec{X} \in S$

where

TUS $=$ Total User Satisfacation

$\mathrm{TC}=$ Total Cost

NTUP $_{n}=$ Normalized total User Preferences for vendor $n$

$\mathrm{TC}_{\mathbf{n}}=$ Total Cost of vendor $\mathrm{n}$

$\mathrm{S}=$ Feasible region

$$
X_{n}=\left\{\begin{array}{ll}
1 & \text { if vendor } n \text { is selected } \\
0 & \text { otherwise }
\end{array}\right. \text {. }
$$

To resolve this problem, a strategy that parallels preemptive goal programming is employed. The first sub-problem will treat the highest priority 
objective as the objective function. The constraints will include the secondary objective at a threshold level and, if needed, a threshold level for the primary objective as well. For example, suppose that there is a minimum acceptable level for TUS, a maximum acceptable TC, and that TUS is the primary objective. The first sub-problem that must be solved would be:

Maximize TUS $=\sum_{n=1}^{N} N T U P_{n}{ }^{*} X_{n}$

st

$\sum_{n=1}^{N} T C_{n}^{*} X_{n} \leq T C_{\operatorname{maximum}}$

$\sum_{n=1}^{N} N T U P_{n} * X_{n} \geq T U S_{\operatorname{minimum}}$

$\vec{X} \in S$

$X_{n} \in(0,1) \vee n$

where,

$\mathrm{TC}_{\text {maximum }}=$ Maximum allowable value of $\mathrm{TC}$ initially specified by the decision maker

TUS $S_{\text {minimum }}=$ Minimum allowable value of TUS initially specified by the decision maker

The solution to this problem would yield an optimum value of TUS* which is then treated as the target TUS for the second sub-problem in which minimizing TC is the objective.

Minimize $\mathrm{TC}=\sum_{n=1}^{N} T C_{n} * X_{n}$

st

$\sum_{n=1}^{N} T C_{n}^{*} X_{n} \leq T C_{\operatorname{maximum}}$

$\sum_{n=1}^{N} N T U P_{n} * X_{n} \geq T U S_{\text {minimum }}$

$\vec{X} \in S$

$X_{n} \in(0,1) \vee n$

Theresulting solution represents the best choice for the decision maker. 
In real situations, however, it is unusual that the model can capture all aspects that a human decision maker must consider before a final selection is made. As such, providing only one solution is frequently undesirable. An alternative is to provide a number of feasible, compromise solutions that allows the decision maker to consider the strengths and weaknesses of each and integrate this information into the broader concerns of the decision making process. To achieve this objective, we propose a sequential relaxation of the target value in the second sub-problem that relates to the optimal value from the first sub-problem. In the above example, alternative solutions would be generated by repeatedly solving the second sub-problem as the value of TUS $_{\text {target }}$ is relaxed to decreasing levels. The decision maker is then presented a series of compromise solutions from which he or she can proceed having a quantitative-based starting point.

\section{Illustrative example}

In this section, application of the proposed approach to an electronic components manufacturer that wished to replace its legacy information system with a state-of-the art ERP product is displayed. (Upon the company's request, we keep the name of the company confidential). The company is located in the southern part of the USA. The main purpose of this endeavor was to select an ERP product that would comprehensively serve all computing needs of this midsized company whose customers are industrial distributors and OEMs (Original Equipment Manufacturers).

The first step in the selection process was to form a cross-functional team with a representative from each functional area to determine performance aspects and enablers and to gather the required data. The cross functional team with 5 members was then organized and trained on how to use the proposed KBDS tool. Especially, some members with the basic mathematical programming background assisted us a great deal in explaining the power and the robustness of this tool.

Once the team obtained the necessary knowledge about the tool, the discussion processes started and the team agreed that the evaluation criteria ought to be comprehensive and relevant for an ERP software selection of a midsized electronic components manufacturer. After conducting some brainstorming sessions through team meetings and the company intranet, 4 performance aspects and 17 enablers as listed in Table 3 were identified that would be employed in further steps of the KBDS tool. The main objective of the team, in these sessions, was to account for the varying needs of each department. 
The following is the demonstration of translating input into parameters that can be used in a multiobjective model to seek the best ERP product for the company.

\subsection{The importance of performance aspects}

Once performance aspects and enablers have been determined, opinions of 5 team members have been obtained in the form of linguistic variables such as "very strong", "strong", "medium", "weak" and "none" for each performance aspect as shown in Table 3 .

\begin{tabular}{|l|l|}
\hline Performance Aspects & Number of Responses \\
\hline Capability & 4 Very strong, 1 strong \\
\hline Reliability & 5 Very strong \\
\hline Credibility & 4 Medium, 1 strong \\
\hline Service & 4 Strong, 1 Very strong \\
\hline
\end{tabular}

Table 3: Frequency of Expert responses

For example, as four members considered capability "very strong", one claimed that it is a strong performance aspect. Then, dcapability is calculated using equation (4) as follows

$d_{\text {capability }}=\frac{\sum_{m=1}^{4} \operatorname{MCS}\left[\text { triang }\left(\mathrm{LV}_{\text {very strong }}^{\mathrm{m}}\right)\right]+\mathrm{MCS}\left[\text { triang }\left(\mathrm{LV}_{\text {strong }}\right)\right]}{5}$
$=\frac{9.04+9.68+9.78+9.6+5.86}{5}=8.79$

Note that performance aspects that are represented by linguistic variable very strong are valued most by team members. The importance of each performance aspect was calculated in the same way using the inputs in Table 3. The normalized values for the importance of the performance aspects are provided in Table 4. 


\begin{tabular}{|c|c|}
\hline Performance Aspects & Normalized Importance \\
\hline Capability & 0.29 \\
\hline Reliability & 0.30 \\
\hline Credibility & 0.17 \\
\hline Service & 0.24 \\
\hline
\end{tabular}

Table 4: The normalized values for the importance of the performance aspects

\subsection{Relationship scores}

Team member opinions have also been received regarding the relationship between performance aspects and enablers. For example, 5 members claimed that the relationship between capability and increased transparency is very strong. Then, $R_{\text {capability-increased transparency was calculated }}$ using equation (3)

$$
\begin{aligned}
\mathrm{R}_{\text {capability-increased transparency }}=\frac{\sum_{m=1}^{5} M C S\left[\text { triang }\left(\mathrm{LV}_{\mathrm{very}}^{\mathrm{m}} \text { strong }\right)\right]}{5} \\
=\frac{7.8+8.82+9.8+9.46+9.55}{5}=9.086
\end{aligned}
$$

Once dis and Rijs have been calculated, the ATIRs and RTIRs were computed. As an example, consider the enabler "increased organizational flexibility" in which equations (1) and (2) yield,

$$
\begin{aligned}
& \text { ATIR }_{\text {increased organizational flexibility }}=0.29 * 9.17+0.3 * 8.84=162 \\
& \text { RTIR }_{\text {increased organizational flexibility }}=162 / 2171.113=0.07
\end{aligned}
$$

The results of the calculations for the remaining enablers are shown in Table 5 (Fuzzy QFD).

Once RTIRs have been obtained, the TUPs and NTUPs that will be input to the multi-objective modeling were calculated by using RFQs, RFPs and RFIs that summarize the technical requirements for potential vendors. At this point, screening, which is very useful in cutting down the dimensions of the decision problem, was used. The company initially received 50 RFQs, RFPs and (or) RFIs back from software vendors. However, 30 of them failed to meet some of the preliminary conditions of enablers and (or) cost, and they were rejected preemptively. As illustrated in Table 6, the table of TUPs consists of the possible ERP vendors arrayed across the top and the enablers listed along the side. In this example, the team considered 17 enablers from the fuzzy QFD process and 20 alternative vendors as candidates after screening. 


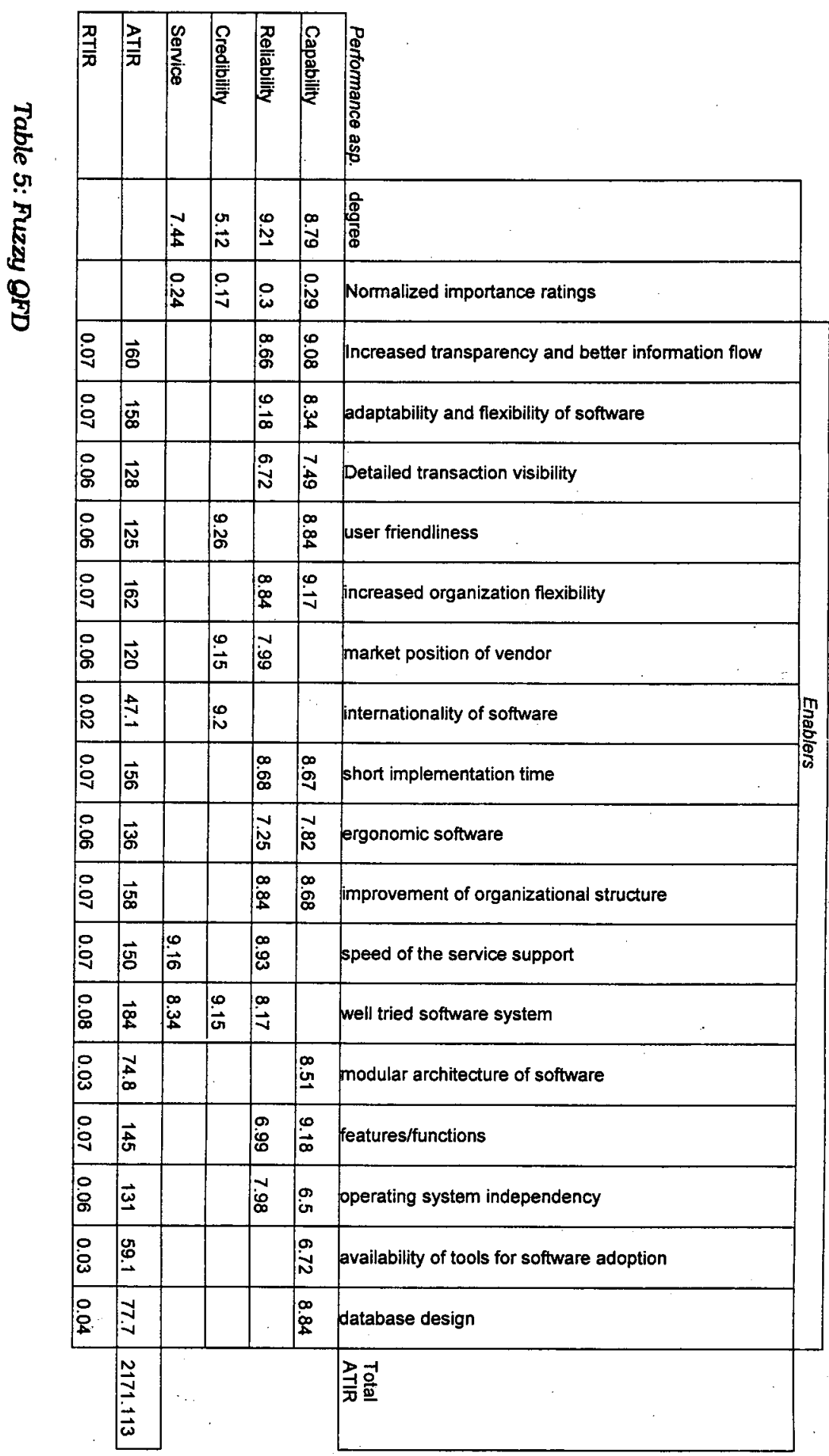




\begin{tabular}{|c|c|c|c|c|c|c|c|c|c|c|c|c|c|c|c|c|c|c|c|c|}
\hline CRITERIA & V1 & $\mathrm{V} 2$ & V3 & V4 & V5 & V6 & V7 & V8 & V9 & $V_{10}$ & V11 & $\mathrm{V} 12$ & V13 & V14 & V15 & $V_{16}$ & V17 & V18 & V19 & $\mathrm{V}_{20}$ \\
\hline Incr. transp. & 0.61 & 0.493 & 0.5 & 0.654 & 0.434 & 0.625 & 0.397 & 0.654 & 0.36 & 0.492 & 0.507 & 0.654 & 0.434 & 0.669 & 0.287 & 0.5 & 0.537 & 0.448 & 0.448 & 0.573 \\
\hline adapta. & 0.647 & 0.502 & 0.545 & 0.429 & 0.356 & 0.667 & 0.647 & 0.429 & 0.356 & 0.567 & 0.284 & 0.356 & 0.647 & 0.574 & 0.356 & 0.567 & 0.647 & 0.407 & 0.516 & 0.502 \\
\hline Detailed trans. & 0.524 & 0.477 & 0.441 & 0.424 & 0.406 & 0.482 & 0.347 & 0.512 & 0.282 & 0.288 & 0.465 & 0.506 & 0.371 & 0.535 & 0.271 & 0.524 & 0.171 & 0.429 & 0.477 & 0.477 \\
\hline user friendliness & 0.334 & 0.501 & 0.45 & 0.432 & 0.398 & 0.34 & 0.277 & 0.501 & 0.409 & 0.363 & 0.455 & 0.398 & 0.421 & 0.334 & 0.34 & 0.536 & 0.323 & 0.265 & 0.548 & 0.496 \\
\hline increased org. & 0.515 & 0.684 & 0.455 & 0.396 & 0.366 & 0.366 & 0.679 & 0.59 & 0.388 & 0.336 & 0.485 & 0.291 & 0.56 & 0.187 & 0.515 & 0.358 & 0.343 & 0.306 & 0.306 & 0.56 \\
\hline market position & 0.438 & 0.433 & 0.449 & 0.327 & 0.383 & 0.438 & 0.377 & 0.477 & 0.272 & 0.338 & 0.349 & 0.477 & 0.327 & 0.455 & 0.405 & 0.327 & 0.283 & 0.338 & 0.283 & 0.255 \\
\hline internationality & 0.176 & 0.171 & 0.171 & 0.15 & 0.158 & 0.128 & 0.163 & 0.187 & 0.137 & 0.15 & 0.169 & 0.187 & 0.189 & 0.187 & 0.165 & 0.171 & 0.158 & 0.098 & 0.154 & 0.143 \\
\hline short impl. & 0.424 & 0.496 & 0.547 & 0.539 & 0.367 & 0.467 & 0.518 & 0.496 & 0.59 & 0.496 & 0.352 & 0.547 & 0.547 & 0.424 & 0.568 & 0.467 & 0.439 & 0.618 & 0.439 & 0.618 \\
\hline ergonomics & 0.577 & 0.406 & 0.431 & 0.337 & 0.35 & 0.468 & 0.431 & 0.431 & 0.331 & 0.268 & 0.243 & 0.431 & 0.393 & 0.35 & 0.331 & 0.449 & 0.487 & 0.474 & 0.468 & 0.35 \\
\hline improvement & 0.552 & 0.429 & 0.567 & 0.53 & 0.596 & 0.523 & 0.356 & 0.632 & 0.385 & 0.472 & 0.552 & 0.639 & 0.479 & 0.647 & 0.276 & 0.501 & 0.443 & 0.53 & 0.443 & 0.625 \\
\hline serv. Speed & 0.596 & 0.52 & 0.575 & 0.492 & 0.526 & 0.478 & 0.526 & 0.61 & 0.492 & 0.478 & 0.478 & 0.63 & 0.617 & 0.61 & 0.54 & 0.568 & 0.617 & 0.617 & 0.596 & 0.506 \\
\hline well tried softw. & 0.687 & 0.721 & 0.687 & 0.602 & 0.619 & 0.721 & 0.645 & 0.755 & 0.577 & 0.577 & 0.645 & 0.729 & 0.687 & 0.704 & 0.645 & 0.661 & 0.602 & 0.5 & 0.636 & 0.475 \\
\hline modular architec. & 0.296 & 0.272 & 0.169 & 0.258 & 0.214 & 0.2 & 0.296 & 0.279 & 0.272 & 0.258 & 0.169 & 0.296 & 0.238 & 0.272 & 0.169 & 0.282 & 0.296 & 0.248 & 0.279 & 0.262 \\
\hline feautures & 0.501 & 0.461 & 0.394 & 0.461 & 0.481 & 0.408 & 0.508 & 0.508 & 0.341 & 0.474 & 0.394 & 0.575 & 0.354 & 0.581 & 0.327 & 0.481 & 0.307 & 0.441 & 0.301 & 0.374 \\
\hline operating system & 0.475 & 0.427 & 0.391 & 0.451 & 0.355 & 0.475 & 0.487 & 0.295 & 0.536 & 0.271 & 0.295 & 0.415 & 0.536 & 0.403 & 0.415 & 0.337 & 0.307 & 0.457 & 0.277 & 0.379 \\
\hline availab. of tools & 0.188 & 0.204 & 0.188 & 0.161 & 0.106 & 0.193 & 0.22 & 0.231 & 0.139 & 0.161 & 0.188 & 0.193 & 0.231 & 0.234 & 0.242 & 0.234 & 0.22 & 0.234 & 0.215 & 0.125 \\
\hline database design & 0.312 & 0.312 & 0.312 & 0.247 & 0.312 & 0.211 & 0.312 & 0.312 & 0.312 & 0.211 & 0.247 & 0.312 & 0.312 & 0.312 & 0.175 & 0.243 & 0.272 & 0.272 & 0.201 & 0.211 \\
\hline TUP & 7.852 & 7.509 & 7.27 & 6.891 & 6.425 & 7.191 & 7.186 & 7.897 & 6.178 & 6.202 & 6.278 & 7.636 & 7.341 & 7.477 & 6.027 & 7.209 & 6.452 & 6.685 & 6.585 & 6.93 \\
\hline NTUP & 0.056 & 0.054 & 0.052 & 0.049 & 0.046 & 0.052 & 0.052 & 0.057 & 0.044 & 0.045 & 0.045 & 0.055 & 0.053 & 0.054 & 0.043 & 0.052 & 0.046 & 0.048 & 0.047 & 0.05 \\
\hline
\end{tabular}

Table 6: TUPS and NTUPs for each vendor 
The entries in Table 6 are the TUP and NTUPs associated with each enabler for each software package. For example, average of the Monte Carlo simulation values for the linguistic variable "very strong" that the project team used to describe the enabler "detailed transaction visibility" was 8.9. Then,

TUP detailed transaction visibility $-\mathrm{V}_{1}=\mathrm{RTIR}_{\text {detailed transaction visibility }}$

*WA detailed transaction visibility $-\mathrm{V}_{1}=0.06 * 8.9=0.525$

Then, NTUP is calculated using equation (6);

$N T U P_{\text {det ailed transaction visibility- } \mathrm{V} 1}=\frac{7.852}{139.22}=0.056$

This process was repeated until TUP and NTUP values computed for each possible enabler - alternative pair. The results are displayed in Table 6.

\subsection{Multi-Objective modeling}

Once the first and second elements of KBDS tool were completed, the company, in this phase, used the cost information included in the RFQs and balanced the cost of the ERP software against the NTUPs. Note that the cost values are simplified to facilitate readers' understanding. The costs of the products obtained from RFQs for the products are displayed in Table 7.

\begin{tabular}{|l|ll|}
\hline Vendor 1 & $\$$ & $195,000.00$ \\
\hline Vendor 2 & $\$$ & $175,000.00$ \\
\hline Vendor 3 & $\$$ & $159,000.00$ \\
\hline Vendor 4 & $\$$ & $155,000.00$ \\
\hline Vendor 5 & $\$$ & $145,000.00$ \\
\hline Vendor 6 & $\$$ & $153,000.00$ \\
\hline Vendor 7 & $\$$ & $168,000.00$ \\
\hline Vendor 8 & $\$$ & $200,000.00$ \\
\hline Vendor 9 & $\$$ & $138,000.00$ \\
\hline Vendor 10 & $\$$ & $125,000.00$ \\
\hline Vendor 11 & $\$$ & $156,000.00$ \\
\hline Vendor 12 & $\$$ & $165,000.00$ \\
\hline Vendor 13 & $\$$ & $156,000.00$ \\
\hline Vendor 14 & $\$$ & $155,000.00$ \\
\hline
\end{tabular}




\begin{tabular}{|l|ll|}
\hline Vendor 15 & $\$$ & $141,000.00$ \\
\hline Vendor 16 & $\$$ & $160,000.00$ \\
\hline Vendor 17 & $\$$ & $150,000.00$ \\
\hline Vendor 18 & $\$$ & $152,000.00$ \\
\hline Vendor 19 & $\$$ & $145,000.00$ \\
\hline Vendor 20 & $\$$ & $165,000.00$ \\
\hline
\end{tabular}

Table 7: Total cost for each vendor's software

The project team then selected NTUP as the most important criterion and $\mathrm{TC}$ as the secondary criterion. They also decided along with the managers in accounting department that TC must not be greater than $\$ 183,000$. Since the NTUP has been selected as the most important criterion, the first problem to be solved was:

Maximize NTUP $=\sum_{i=1}^{20} N T U P_{i}^{*} X_{i}$

st

$$
\begin{aligned}
& \sum_{i=1}^{20} C_{i}{ }^{*} X_{i} \leq 183,000 \\
& X_{i} \in(0,1) \mathrm{i}=1, \ldots, 20
\end{aligned}
$$

The optimal solution to this problem was NTUP $=0.0548 \mathrm{TC}^{*}=\$ 165,000$ and $\mathrm{X}^{*}$ = Vendor 12 .

The next problem was formulated relaxing NTUP to 0.053 and minimizing TC as the objective function. Note that decreased NTUP value was used as a constraint.

$$
\text { Minimize TC }=\sum_{i=1}^{20} T C_{i}^{*} X_{i}
$$

st

$$
\begin{aligned}
& \sum_{i=1}^{20} N T U P_{i}{ }^{*} X_{i} \geq 0.053 \\
& \sum_{i=1}^{20} T C_{i} \leq 165 \\
& X_{i} \in(0,1) \mathrm{i}=1, \ldots, 20
\end{aligned}
$$

The optimal solution is $\mathrm{TC}^{*}=\$ 155,000 \mathrm{NTUP}=0.0537$ and the company should choose vendor 14 . 
By further relaxing the minimum acceptable NTUP, another alternative solution was generated as described previously and illustrated in Table 8. An important feature of the methodology was that the company would make a decision not only knowing the optimal solution for the preconceived target for the objective but also a quantitative sense for the tradeoff associated with accepting a lower level of NTUP to save some money. This type of information is invaluable in decision-making processes like software, material, vendor and equipment selection.

\begin{tabular}{|c|c|c|}
\hline NTUP & TC & Selected Vendor \\
\hline 0.0548 & $\$ 165,100.00$ & Vendor 12 \\
\hline 0.0537 & $\$ 155,000.00$ & Vendor 14 \\
\hline 0.0517 & $\$ 153,000.00$ & Vendor 16 \\
\hline
\end{tabular}

Table 8 Alternative solutions

Once the alternative vendors were generated using the multiobjective model, the company decided to analyze their products broadly by downloading the demonstration copies from their Web sites and performing a comprehensive benefit analysis to finalize the selection process.

\section{Discussion of the implications}

An important advantage of the proposed multi-objective strategy is that it generates preferred alternatives while maintaining all parameters at acceptable levels. For example, user satisfaction is not sacrificed to an undesirable level to improve total cost. On the other hand, if the acceptable levels of the parameters cannot be satisfied, the problem clearly becomes infeasible and the decision maker must look for other alternatives or must modify inputs to the model. We believe that these features make this approach attractive to managers or practitioners.

In addition, the KBDS tool is based on a spreadsheet format that includes Monte Carlo simulation and a solver, which makes it easy to operate and affordable. However, it is imperative to note that the proposed KBDSS is a tool that is a part of a process not the complete process. In essence, for complex selections, such as this one, the decision maker-tool combination must work together to drive the solution since it is impossible to include every aspect of the selection process in the model. In addition, long term effects of the products on the company's bottom-line must be considered before a final decision is made. If this is achieved effectively, the results benefit the process and the pitfalls of past selection processes are avoided. 
The second element of the proposed tool, fuzzy QFD, enabled the organization to develop a concurrent working environment. Cross functional team members considered QFD structure very useful in team-based decision making processes and they contended that (1) the underlying idea behind QFD is based on team work, (2) it helped the team effectively use the other technical tools to support and complement each other and address the priority issue (3) It helped to pinpoint those areas of user concern where the team involvement and the use of specialized tools could be most beneficial, and (4) because QFD had its origin with the user, it assisted the organization in gaining user focus. It was only through this focus that the organization began to understand what was needed to increase user satisfaction.

Further, the third element of the KBDS tool, a multiobjective model, was found to be valuable due to its simple structure and what-if capabilities. As highlighted previously, two members' basic knowledge of mathematical programming facilitated the training sessions and enabled us to better communicate the capabilities of the proposed approach to the team while trying to satisfy multiple objectives that conflict.

\section{Conclusion}

Purchasing an information system, such as ERP is a project with significant financial impact and involves making a decision based on both qualitative and quantitative information. Due to the significance of such a project, this study attempted to propose KBDS tool to alleviate the difficulties encountered in ERP software selection projects. Further, a real case of an electronic component manufacturer's ERP selection process that used the proposed approach to assist the company was presented and discussed. KBDS tool was successfully used to narrow down the alternatives considered by the company. However, as emphasized before, the proposed tool does not substitute for a comprehensive benefit analysis to finalize the selection process in terms of long-term results of implementing alternative software packages. Also, we strongly believe that using demonstration copies and performing a detailed long-term benefit analysis before making the final decision is invaluable.

\section{References}

ANTHONY, T.F. / BUFFA, F.P. (1977), "Strategic purchase scheduling." Jurnal of Purchasing and Materials Management, Spring: 27-31.

AKAO, Y. (1990), Quality Function Deployment: Integrating customer requirements into Product Design (Cambridge, Massachusetts: Productivity Press). 
Lemail Erol - Mehmat Barut • Developing Knowledge Based Decision Support Tool for Enterprise Resourcas • 95

BERNROIDER, E. / KORCH, S. (2001), "ERP selection process in midsize and large organizations," Business Process Management Joumal, Vol. 7, No. 3 : 251 - 257.

BUIFA, F.P. (1983), "Strategic purchese schedulling," Joumal of Purchasing and Materials Management, Fall: $31-40$.

CHEN, S. J. / HWANG, C. L (1992), Fuzzy Multiple Attribute Decision Making: Method and Applications (New York: Springer-Verlog).

FIORE, J. (1999), APICS Performance Advantage, September: 12-15.

GHODSYPOUR, S.H. / O'BRIEN, C.O. (1998), 'A decision support system for suppller selection using an Integrated AHP and LP." Intemational bumal of Production Economics, 56.57: 199-212.

HANDFELD, R./ WALTON, S.V. / SROUIFE, R. / MELNYK, S.A. (2002), "Applying environmental criterla to supplier assessment: A study in the application of the Analytical Hilerarchy Process," European Joumal of Operational Research, 141: 70-87.

JUANG, C. H. / HUAANG, X. H. / ELTON, D.J. (1991), "Fuzzy Information Processing by Mote Carlo Simulation technique," Joumal of Civil Engineering Systems, Vol. 8, No.1: 19-25.

KASIUNGAM, R.G. / LEE, C.H. (1996), "Selection of vendors-A mixed-integer programming approach," Computer and Industrial Engineering, 31 : 347-350.

KHOO, L.P / HO, N.C. (1996), "Framework of a Fuzzy Quality Function Deployment System," Intemational Joumal of Production Reseanch, 34: 299-311.

KIM, K. / MOSKOWITZ, H. / DHINGRA, A. / EVANS, G. (2000), "Fuzzy Multu-Criteria models for quality function deployment," European Jumal of Operational Research, 121: 504-518.

KORPELA, J. / LEHMUSVAARA, A. (1999), "A customer oriented approach to warehouse network evaluation and design," Intemational burnal of Production Economics , 59: 135-146.

LAI, V.S. / WONG. B.K. / CHEUNG, W. (2002), "Group Decision Making in a Multiple Criteria environment: A case using the AHP in software selection," European Jumal of Operational Research, 137: 134-144.

LU, M. / MADU, C.N. / WINOKUR, D. (1994), "Integrating QFD, AHP and Benchmarking In strategic marketing," Joumal of Business Industrial Marketing, 9 (1): 41-50.

MASUD, M. Abu (1993). "Using Fuzzy Sets in Quality Function Deployment," $2^{\text {nd }}$ Industrial Engineering Research Corference Proceedings: 270-274.

MIN. H. (1992). "The selection of Software: The Analytic Hierarchy Process," Intemational bumal of Physical Distribution and Logistics Management, Vol. 22 No. 1: 157-165.

MN, J.H. / SCHILUNG, D. (1990), "Multiobjective Analysls of Facility Location Decislons," Eumpean Joumal of Operational Research, 49: 295-307.

MOORE, D.L / FEARON. H.E. (1973), "Computer Assisted Decislon-Making in Purchasing," Jumal of Purchasing, Vol. 9. No. 4 (November): 5-25.

OLSON, D. L (2001), Introduction to Information Systems Project Management (New York: Irwin-McGraw Hill).

PTAK, A.C. / SCHRAGENHEM, E. (2000). ERP Tools, Techriques and Applications for Integrating the Supply Chain (Boce Raton, Florida: CRC Press/APICS Serles on Resource Management, LC).

PAN, A. C. (1989), 'Allocation of Order Quantity among Suppliers," Joumal of Purchasing and Materials Management, .Vol.25, No. 3 (Autumn): 36-39.

PEGDEN, D.C. / SAHONNON, R.E. / SADOWSKI, R.P. (1995), Introduction to Simulation Clsing Siman (New York: MkGraw Hill). 
SOHN, S. Y. / CHOI, I. S. (2001), "Fuzzy QFD for supply chaln management with rellability conalderation." Reliability Engineering and System Safety. 72: 327.334.

SHEUY, G. B. / CASHMAN, T. J. / VERMAAT, M. E (2002), Discovering Computers 2002: Concepts for a Digital World (Course Technology, Thomas Leaming).

TEMPONI, C. / YEN, J. / TIAO, W. A. (1999), "House of Quality: A fuzzy loglc based requirement analysis," European bumal of Operational Research, 117: 340-354.

THOMPSON, K.N. (1990), "Vendor profle analysis," Joumal Of Purchasing and Materials Management, Winter: 11-18.

VANEGAS, L. V. / LABIB, A. W. (2001). "A Fuzzy Quality Function Deployment model for deriving optimum targets," Intemational Joumal of Production Research, Vol. 39, No.1: 99-120.

WEBER, C.E. / CURRENT, J.R. (1993), "A mult objective approach to vendor selection," European Jumal of Operations Research, 68: 173-184.

WEBER, C.E. / CURRENT, J.R. / BENTON, W.C. (1991), "Vendor Selection Criteria and Methods," Eunopean Joumal of Operations Research, 50: 2-18. 